\title{
Poly(3-hydroxybutyrate) influences biofilm formation and motility in the novel Antarctic species Pseudomonas extremaustralis under cold conditions
}

\author{
Paula M. Tribelli • Nancy I. López
}

Received: 4 March 2011/Accepted: 26 May 2011/Published online: 11 June 2011

(C) Springer 2011

\begin{abstract}
Polyhydroxyalkanoates (PHAs) are highly reduced bacterial storage compounds that increase fitness in changing environments. It has previously shown that polyhydroxybutyrate (PHB) accumulation is essential during the growth under cold conditions. In this work, the relationship between PHB accumulation and biofilm development at low temperature was investigated. P. extremaustralis, an Antarctic strain able to accumulate PHB, and its phaC mutant, impaired in the synthesis of this polymer, were used to analyze microaerobic growth, biofilm development, EPS content and motility. PHB accumulation increased motility and survival of planktonic cells in the biofilms developed by $P$. extremaustralis under cold conditions. Microaerobic conditions rescued the cold growth defect of the mutant strain. The PHB accumulation capability could constitute an adaptative advantage for the colonization of new ecological niches in stressful environments.
\end{abstract}

Keywords Biofilms $\cdot$ Polyhydroxybutyrate ·

Pseudomonas $\cdot$ Cold $\cdot$ Motility

\section{Introduction}

Bacterial biofilms are known as complex bacterial communities embedded in a polysaccharide matrix and

Communicated by A. Driessen.

P. M. Tribelli · N. I. López $(\bowtie)$

Departamento de Química Biológica, Facultad de Ciencias

Exactas y Naturales, Universidad de Buenos Aires, Intendente

Güiraldes 2160, C1428EGA Buenos Aires, Argentina

e-mail: nan@qb.fcen.uba.ar attached to a surface (Costerton et al. 1995). It is becoming increasingly clear that biofilms have an enormous impact on bacterial survival as they are the preferred lifestyle in natural and artificial environments. Biofilm formation represents a protected lifestyle that allows cells to survive in hostile environments, to cope with the stress, and to disperse to colonize new niches (Decho 2000). In medicine, biofilms represent one of the major problems due to the higher resistance of biofilm-associated bacteria to antimicrobial compounds giving rise to serious nosocomial infections (Mah and O'Toole 2001). In comparison to planktonic cells, biofilms show increased resistance to several stress factors such as reactive oxygen species (ROS) derived from antibiotic action or from $\mathrm{H}_{2} \mathrm{O}_{2}$ exposure, high osmotic pressure and extreme $\mathrm{pH}$ (Lapaglia and Hartzell 1997; Wai et al. 1998; Cochran et al. 2001, Albesa et al. 2004) and is also believed to protect bacterial cells from protozoa predation (Matz and Kjelleberg 2005).

The extent of attachment of microbial cells is a complex process that is influenced by several factors including cell surface hydrophobicity, presence of fimbriae and flagella, production of exopolysaccharides (EPS), metabolism of carbon polymers and microaerobic respiration (Pratt and Kolter 1998; Donlan 2002; Van Alst et al. 2007). Motility is a key factor in biofilm development. It has been demonstrated that flagella motility is required for biofilm formation by $P$. aeruginosa PA14, and that type IV pili is important for microcolony formation (O'Toole and Kolter 1998). P. aeruginosa can develop three types of movement: swarming, swimming, and twitching motility (Klausen et al. 2003). Swarming is important for movement across semisolid surfaces (Kohler et al. 2000) and is influenced by type IV pili and flagella (Shrout et al. 2006). Swimming is a movement in liquid medium by means of flagella; and twitching motility, powered by extension and 
retraction of type IV pili, is involved in microcolony formation which drives cell aggregation (Klausen et al. 2003).

Pseudomonas extremaustralis is a highly stress-resistant bacterial strain isolated from an Antarctic environment (López et al. 2009) that is able to synthesize polyhydroxyalkanoates (PHA), carbon and energy reserve polymers that are produced under imbalanced growth conditions. PHAs are interesting since their involvement in survival under different stress conditions and their plastic and elastomeric characteristics similar to petroleum derivative plastics (Hazer and Steinbüchel 2007). P. extremaustralis is able to synthesize polyhydroxybutyrate (PHB), the most studied PHA, using octanoate and other fatty acids, but not glucose, as carbon sources (Ayub et al. 2006). In this species, pha genes are organized in a cluster, containing genes phaR, phaB, phaA (a defective $\beta$-ketothiolase), and $p h a C$, and are located within a genomic island (Ayub et al. 2007) that also encloses other genes probably related with the adaptability to stress conditions. In P. extremaustralis, PHB is essential for bacterial growth under low temperature and to tolerate the oxidative stress derived from cold (Ayub et al. 2009). Studies from our laboratory demonstrated that $P$. extremaustralis is able to grow under low oxygen conditions (Tribelli et al. 2010), similar to those found it in biofilms (Xu et al. 1998).

Cold environments constitute stressful habitats that limit the bacterial survival and the colonization of new ecological niches due to the effect of unfavorable conditions impacting on physical and biochemical cellular process. Exposure to these conditions provokes changes in solubility, reaction kinetics, membrane fluidity, degradation, protein stability, conformation, and gene expression (D'Amico et al. 2006; Strocchi et al. 2006). As a result, bacteria that live in such conditions must have some physiological adaptations. The aim of this work was to investigate the relationship between PHB and biofilm development during growth under cold conditions. We also analyzed EPS content and motility as relevant characteristics of biofilm formation at low temperature.

\section{Materials and methods}

Bacterial strains and culture conditions

Pseudomonas extremaustralis DSM $17835^{\mathrm{T}}$ (López et al. 2009), a phaC mutant and a complemented strain containing the plasmid pBBR1MSC carrying the phaC gene (Ayub et al. 2009) were grown in nutrient broth (NB) supplemented with $15 \mathrm{mM}$ sodium octanoate, incubated overnight at $28^{\circ} \mathrm{C}$ and used as initial inocula. In order to analyze the effect of different oxygen levels, cultures were grown under three different aeration conditions, defined as follows. Standard aerobiosis was achieved using a 1:5 medium volume/Erlenmeyer flask volume ratio with vigorous rotatory agitation $(200 \mathrm{rpm})$. For microaerobiosis, $100 \mathrm{ml}$ bottles were filled with $25 \mathrm{ml}$ (slight microaerobiosis) or $50 \mathrm{ml}$ of medium (moderate microaerobiosis) and slow shaking $(100 \mathrm{rpm})$ in order to avoid cellular aggregation. This experimental design was similar to that described in Lüthi et al. (1986) and Pessi and Haas (2000). Initial optical density was $0.05\left(\mathrm{OD}_{600 \mathrm{~nm}}\right)$. All cultures were incubated at $10^{\circ} \mathrm{C}$ during $30 \mathrm{~h}$ and growth was monitored by measuring $\mathrm{OD}_{600 \mathrm{~nm}}$. Results were expressed as growth rate $(\ln \mathrm{OD} / \mathrm{h})$. PHB accumulation was qualitatively monitored at $\mathrm{OD}=0.5$ by staining with Nile Blue (Ostle and Holt 1982).

\section{Biofilms experiments}

Static biofilms were developed in polystyrene microplates during $72 \mathrm{~h}$. Precultures used as inocula were grown in NB with sodium octanoate (PHB accumulation condition) or $15 \mathrm{mM}$ glucose (PHB non-accumulation condition). Initial optical density was $0.025\left(\mathrm{OD}_{600 \mathrm{~nm}}\right)$. Planktonic cells were collected and $\mathrm{OD}_{600}\left(A_{\mathrm{PL}}\right)$ was measured. The attached biofilm was stained with crystal violet $(\mathrm{CV})$ as described (O'Toole and Kolter 1998) and the total attached biomass $\left(\mathrm{CV}_{550 \mathrm{~nm}}\right)$ was determined.

Total cell counts (planktonic and surface attached cells) were determined using eight wells as experimental unit. Bacterial number was determined by colony counts on nutrient agar (NA) plates, incubated at $28^{\circ} \mathrm{C}$. Planktonic cells were obtained by extracting with a pipette the free cells in the culture medium of each well. Surface attached cells were removed with sterile physiological solution and the resulting suspension was disrupted by vortexing during 20 min. The ratio $\left(C_{\mathrm{A} / \mathrm{P}}\right)=$ colony forming units of attached cells (CFUA)/colony forming units of planktonic cells (CFUP) was calculated.

\section{Exopolysaccharides determination}

Exopolysaccharides formation was measured using anthrone reagent (Quelas et al. 2006). Briefly, $1 \mathrm{ml}$ of culture, obtained from 8 wells as an experimental unit, was centrifuged for $40 \mathrm{~min}$ at $9,500 \mathrm{rpm}$ at $4^{\circ} \mathrm{C}$. The supernatant was transferred to an assay tube and 3 volumes of absolute ethanol were added. The mix was maintained overnight at $-20^{\circ} \mathrm{C}$ and after this, centrifuged for $40 \mathrm{~min}$ at $4^{\circ} \mathrm{C}$. The supernatant was discarded and the pellet was resuspended in $0.5 \mathrm{M} \mathrm{NaCl}$. Different aliquots of each preparation were used to determine reducing monosaccharides with $0.2 \% \mathrm{w} / \mathrm{v}$ of anthrone in $95 \% \mathrm{H}_{2} \mathrm{SO}_{4}$ by measuring absorbance at $620 \mathrm{~nm}$ (Trevelyan and Harrison 1952). Glucose was used as a standard. The EPS content 
was normalized to the cell growth by measuring the total $\mathrm{OD}_{600}$ of the experimental unit and a ratio EPS/OD 600 was determined.

\section{Motility assays}

One colony of $P$. extremaustralis grew in PHB accumulating (with octanoate as carbon source) or non-accumulating conditions (with glucose as carbon source) was used as inocula for motility experiments using a sterile toothpick. The culture media used for the different mobility assays were:

Swimming: tryptone broth $(10 \mathrm{~g} / \mathrm{l}$ tryptone and $5 \mathrm{~g} / \mathrm{l}$ $\mathrm{NaCl})$ containing $0.3 \%(\mathrm{wt} / \mathrm{vol})$ agarose. Swarming: NB $(8 \mathrm{~g} / \mathrm{l})$ solidified with $0.5 \%(\mathrm{wt} / \mathrm{vol})$ agar-agar. Twitching: LB broth (10 g/l tryptone, $5 \mathrm{~g} / \mathrm{l}$ yeast extract, $10 \mathrm{~g} / \mathrm{l} \mathrm{NaCl})$ solidified with $1 \%(\mathrm{wt} / \mathrm{vol})$ agar-agar. All plates were supplemented with sodium octanoate and incubated at 10 or $28^{\circ} \mathrm{C}$ for 3 and 7 days. The diameter of growth of each strain was measured.

\section{Statistical analysis}

To determine the significance of each treatment, a Student's $t$ test with two tails and $95 \%$ of confidence was used. The $p$ value is indicated in the significant experiments.

\section{Results}

Effect of microaerobiosis on the growth of $P$. extremaustralis under cold conditions

P. extremaustralis is able to survive and grow under cold conditions due its capability to synthesize PHB; we previously showed that a phaC mutant strain was impaired for growth under this condition (Ayub et al. 2009). To further investigate the effect of oxygen availability on growth under cold conditions, the wild type and the phaC mutant strain were grown at 10 and $28^{\circ} \mathrm{C}$ under aerobic and microaerobic conditions. At $28^{\circ} \mathrm{C}$, both strains showed a similar growth rate $(p>0.05)$ that decreased under low oxygen availability (Table 1). By contrast, at $10^{\circ} \mathrm{C}$, only the wild-type strain was capable of growing at all the oxygen levels, while the mutant strain only was able to grow under microaerobic conditions reaching growth rates significantly lower than those of the wild-type strain (Table 1, $p=0.008$ for slight microaerobiosis and $p=0.027$ for moderate microaerobiosis). These growth rates represented an increase in the doubling time $(g)$ of the mutant at $10^{\circ} \mathrm{C}$ in comparison to those found at $28^{\circ} \mathrm{C}$. The values reached $6.6 \pm 1.9 \mathrm{~h}$ at $10^{\circ} \mathrm{C}$ and $1.6 \pm 0.06 \mathrm{~h}$ at $28^{\circ} \mathrm{C}$ for slight microaerobiosis, and $8.3 \pm 1.2$ and $2.2 \pm 0.1 \mathrm{~h}$ at 10 and $28^{\circ} \mathrm{C}$, respectively, for moderate microaerobiosis. Even though this, microaerobic conditions rescued the growth defect of the mutant strain under low temperature. The presence of PHB was detected qualitatively in both temperatures in the wild-type strain in all oxygen conditions.

These results showed that a low oxygen environment allowed for growth under cold conditions without PHB accumulation.

\section{Biofilm formation at cold conditions}

The biofilm is a structured heterogeneous community with oxygen and nutrient gradients in which microaerobic respiration seems to be important (Xu et al. 1998). On the basis of the results obtained in cold microaerobic conditions, we hypothesized that PHB would not be essential for survival when cells are grown in a biofilm. We studied static biofilm formation in P. extremaustralis and phaC mutant. We found that the total number of viable cells in the biofilm was similar in all strains $(p>0.05)$ when the culture was incubated at $28^{\circ} \mathrm{C}$ (Fig. 1a), while at $10^{\circ} \mathrm{C}$ a significant decrease in cell number was observed in the mutant compared with the wild-type strain $(p=0.048$, Fig. 1b). The wild-type strain cultured without octanoate showed similar results to the mutant strain (Fig. 1b). The survival of planktonic cells, free cells in the culture medium in biofilms assays, was similar at $28^{\circ} \mathrm{C}$ with no significant differences between the strains. While at $10^{\circ} \mathrm{C}$ planktonic survival of the mutant strain decreased significantly $(p=0.030)$ in comparison with that observed at
Table 1 Growth rate at 10 and $28^{\circ} \mathrm{C}$ under different aeration conditions

\begin{tabular}{llll}
\hline$T\left({ }^{\circ} \mathrm{C}\right)$ & Condition & \multicolumn{2}{l}{ Growth rate $(\ln \mathrm{DO} / \mathrm{h})$} \\
\cline { 3 - 4 } & & Wild type & phaC \\
\hline 10 & Aerobic & $0.054 \pm 0.006$ & $\mathrm{NG}$ \\
& Slight microaerobic & $0.056 \pm 0.001$ & $0.031 \pm 0.003$ \\
& Moderate microaerobic & $0.055 \pm 0.004$ & $0.034 \pm 0.003$ \\
& Aerobic & $0.33 \pm 0.010$ & $0.33 \pm 0.020$ \\
& Slight microaerobic & $0.19 \pm 0.020$ & $0.16 \pm 0.020$ \\
& Moderate microaerobic & $0.15 \pm 0.020$ & $0.17 \pm 0.020$ \\
\hline
\end{tabular}


Fig. 1 a Bacterial total counts from biofilms experiments at $28^{\circ} \mathrm{C}$. b Bacterial total counts from biofilms experiments at $10^{\circ} \mathrm{C}$. c $C_{\mathrm{A} / \mathrm{P}}$ index (ratio between attached cells and planktonic cells from the biofilms) at 28 and $10^{\circ} \mathrm{C}$. d Crystal violet assay in biofilm cultures at 10 and $28^{\circ} \mathrm{C}$, the OD was measured at $550 \mathrm{~nm}$. All cultures were supplemented with octanoate to allow PHB accumulation and the wild-type strain was also grown in nonaccumulation conditions by adding glucose to the culture medium. Each experiment was performed three times and typical results are presented. Values represent media \pm SD of triplicate measurements
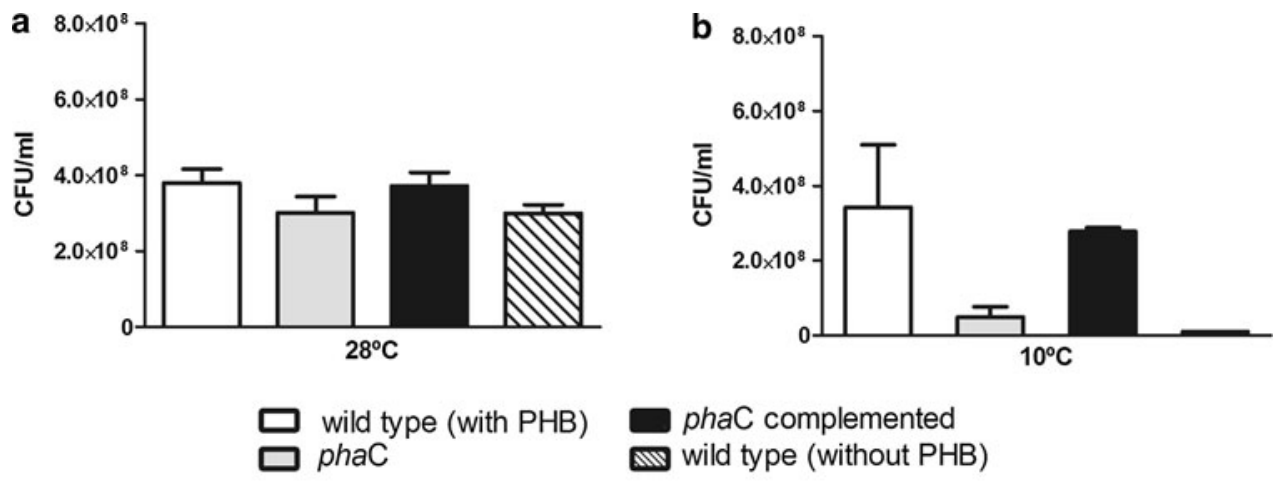

C

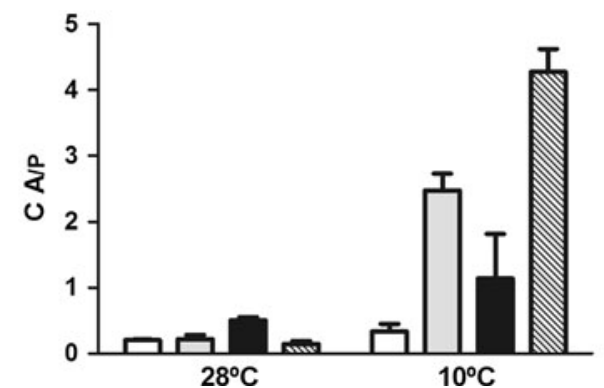

phaC complemented wild type (without $\mathrm{PHB}$ )

d

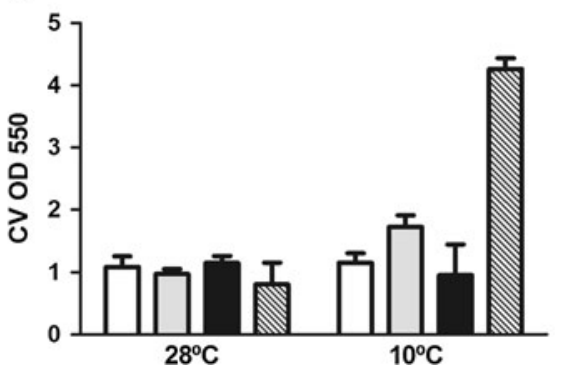

$28^{\circ} \mathrm{C}\left(1.2 \times 10^{6} \pm 5.2 \times 10^{5}\right.$ and $1.9 \times 10^{8} \pm 7.3 \times$ $10^{7} \mathrm{cfu} / \mathrm{ml}$, respectively), the wild-type strain showed similar values at both temperatures $\left(p>0.05,4.4 \times 10^{8} \pm\right.$ $9.9 \times 10^{7}$ and $2.6 \times 10^{8} \pm 8.9 \times 10^{7} \mathrm{cfu} / \mathrm{ml}$ for 28 and $10^{\circ} \mathrm{C}$, respectively).

A significant decrease $(p=0.001)$ was also observed in the wild-type strain under non-PHB accumulating conditions (using glucose as the carbon source) showing values of $1.3 \times 10^{8} \pm 2.1 \times 10^{7} \mathrm{cfu} / \mathrm{ml}$ at $28^{\circ} \mathrm{C}$ and $8.7 \times$ $10^{5} \pm 9.8 \times 10^{4} \mathrm{cfu} / \mathrm{ml}$ at $10^{\circ} \mathrm{C}$.

The complementation with the phaC gene significantly increased the planktonic survival at $10^{\circ} \mathrm{C}$, reaching to a value of $1.9 \times 10^{7} \pm 6.2 \times 10^{5} \mathrm{cfu} / \mathrm{ml}(p=0.038)$.

According to that, the $C_{\mathrm{A} / \mathrm{P}}$ ratio at $28^{\circ} \mathrm{C}$ was similar in all strains (Fig. 1c). The wild-type strain, growing in conditions leading to PHB accumulation, showed a similar $C_{\mathrm{A} / \mathrm{P}}$ value at both temperatures. However, in cold conditions the phaC mutant presented a significant increase in this ratio in comparison to the wild-type strain (Fig. 1c, $p=0.001)$. These results indicate that the mutant strain has a higher number of viable cells in the attached form in comparison with the planktonic state (Fig. 1c). The complementation of the mutant with the phaC gene, allowed for PHB accumulation and restored the wild-type phenotype (Fig. 1c). In addition, cultures of the wild-type strain performed in PHB non-accumulating conditions showed similar values to the mutant strain (Fig. 1c). The biofilm total biomass was also calculated by staining with crystal violet $(\mathrm{CV})$. At $28^{\circ} \mathrm{C}$, the value was similar for all strains with no significant differences. However, at $10^{\circ} \mathrm{C}$, the phaC mutant showed a significant increase in the $\mathrm{CV}$ staining in comparison to that of the wild-type strain and the mutant strain at $28^{\circ} \mathrm{C}, p=0.002$ and $p=0.038$, respectively (Fig. 1d). These results are in accordance with the index calculated by viable counts.

EPS content of static biofilms at low temperature

Biofilm formation depends on several factors, including carbon compounds, therefore, we investigated the exopolysaccharide content (EPS) in both strains. In all strains, the exopolysaccharide content (EPS) was lower at $28^{\circ} \mathrm{C}$ in comparison with the EPS content at $10^{\circ} \mathrm{C}$ (Fig. 2). The EPS production observed for the phaC mutant strain in cold conditions (Fig. 2) was significantly higher than that observed at $28^{\circ} \mathrm{C}(p=0.002)$ and it was also higher in comparison to the EPS content of the wild-type strain at $10^{\circ} \mathrm{C}(p=0.001)$. A similar trend was observed in the wild-type strain under PHB non-accumulating conditions that showed significant differences with the EPS content at 28 and $10^{\circ} \mathrm{C}(p=0.001)$ (Fig. 2$)$. The results of EPS content are in line with the results observed in biofilm experiments.

Effect of cold and PHB accumulation on $P$. extremaustralis motility

Flagella and pili type IV motility is known to be important in biofilm formation. Motility assays were carried out in $P$. extremaustralis wild-type strain using inocula that previously had or had not accumulated PHB. We studied swarming, swimming and twitching movements. After 


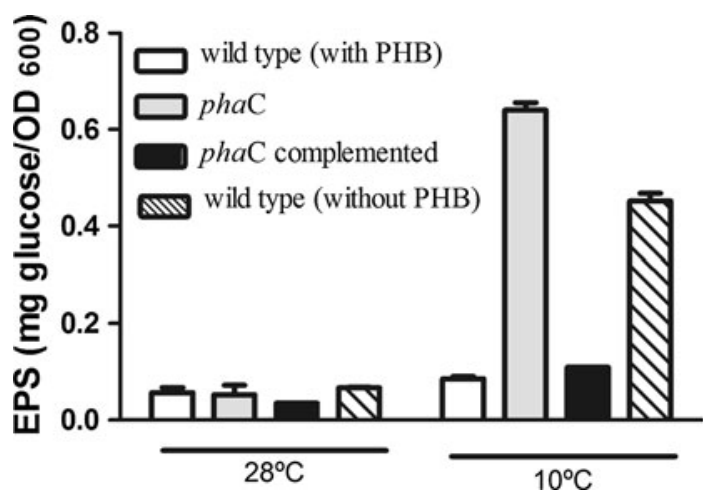

Fig. 2 EPS content at 28 and $10^{\circ} \mathrm{C}$. All cultures were supplemented with octanoate to allow PHB accumulation and the wild-type strain was also cultured in PHB non-accumulation conditions by supplemented the media with glucose instead with octanoate. Each experiment was performed three times and typical results are presented. Values represent media \pm SD of triplicate measurements

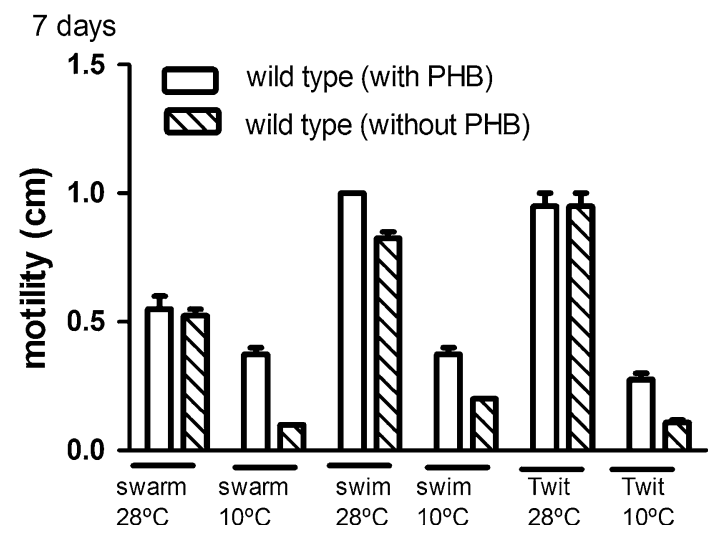

Fig. 3 Motility of $P$. extremaustralis at 28 and $10^{\circ} \mathrm{C}$. All motility plates were supplemented with octanoate as carbon source to allow PHB accumulation. The inocula were prepared using octanoate (with PHB) or glucose (without PHB) as carbon source. Values represent media \pm SD of triplicate measurements. Swar swarming, Swim swimming, Twit twitching

7 days, the wild-type strain in both growth conditions presented similar capability of movement at $28^{\circ} \mathrm{C}$, while at $10^{\circ} \mathrm{C}$ the higher motility was observed when the polymer had been previously accumulated showing significant differences in comparison with the non-accumulation condition (Fig. 3). Interestingly, after 3 days of culture the strain was able to grow and to move at $10^{\circ} \mathrm{C}$ only when it had previously accumulated PHB (data not shown).

\section{Discussion}

Bacteria have developed several strategies to cope with stressful environments, among them accumulation of carbon polymers and biofilm formation have been widely reported (e.g. López et al. 1995; Mah and O'Toole 2001;
Pham et al. 2004; Kadouri et al. 2005). We have previously showed that PHB is essential for growth under cold conditions alleviating the oxidative stress produced at low temperatures (Ayub et al. 2009). In addition, P. extremaustralis is able to grow and accumulate PHB under low oxygen levels (Tribelli et al. 2010). In this study, we showed that PHB accumulation condition allowed the formation of biofilms with a higher number of living planktonic cells in comparison with non polymer production condition, in which cells presented significantly higher total adherent biomass, as was observed by CV staining, and the dependence of microaerobiosis to thrive in the cold. The cold sensitive phenotype of the phaC mutant was due to an insufficient availability of reducing equivalents (Ayub et al. 2009) necessary for the functioning of NADH/ NADPH dependent antioxidant enzymes to cope with the oxidative stress derived from low temperature. The growth defect of the mutant strain could be partially alleviated by decreasing oxygen levels in both biofilm and microaerobic cultures.

Biofilms are organized structures that offer a protective lifestyle due to the extracellular matrix in which the cells are embedded (Costerton et al. 1995). Extracellular polysaccharides and proteins have been shown to be key components of the matrix in addition to extracellular DNA (Branda et al. 2005). The EPS content increased in all strains under cold conditions, with the highest exhibited by the mutant strain in concordance with its higher attached biomass. Low temperature produces ROS and an increase in the activity of key antioxidant enzymes (Chattopadhyay et al. 2011). Our results that showed a lower planktonic cell survival, higher EPS content and also a higher attached biomass at low temperatures agree with previous reports which suggest that EPS could scavenge ROS and other toxic compounds present in the environment (Simpson et al. 1989; Bylund et al. 2006; Wang et al. 2007; Chang et al. 2009). In addition, EPS and PHB production appear to be related as both metabolic pathways consume carbon molecules (Martinez et al. 1997). The defect in PHB production observed in the mutant strain may result in an increase in the availability carbon molecules availability that could redirect PHB production to other metabolic processes such as EPS synthesis. The wild-type strain also showed increased EPS production at low temperature, although the differences were not significant, this trend suggests that EPS could contribute to enhanced survival under these conditions.

A key factor in biofilm development is the capability of motility. In E. coli the role of motility appears to be dual by promoting initial cell-to-surface contact and contributing to the spread of a growing biofilm along an abiotic surface (Pratt and Kolter 1998). In addition, in P. aeruginosa and $P$. putida it was observed that motility is important for the 
dispersion stage in biofilms (Sauer et al. 2002) and also it was shown that hypermotile mutants of $P$. aeruginosa have decreased biofilm formation capability in comparison to the wild type (Caiazza et al. 2007). We found that $P$. extremaustralis at cold conditions exhibited a higher motility when the inoculum had accumulated PHB. These results together with biofilm formation capability at low temperatures could be important to understand the lifestyle of bacteria in the environment.

Natural environments are generally poor in nutrients with transient carbon pulses (Chesson et al. 2004) and PHA accumulation has been detected in these environments (Kadouri et al. 2005). Our results suggest that the PHB accumulation could constitute an advantage for the colonization of new niches by promoting the motility and the viability of planktonic cells. PHA metabolism is a dynamic process since polymerases and depolymerases are concomitantly active, resulting in parallel polymer synthesis and degradation. It has been suggested that the overall PHA flux is governed by intracellular ratios of NADH/NAD and acetyl-CoA/CoA (Ren et al. 2010). The depolymerization process is a source of carbon and reducing equivalents. At cold conditions the PHB depolymerization contribute to maintain the redox state avoiding the oxidative damage of lipids molecules (Ayub et al. 2009).

In this study, we demonstrated that PHB accumulation increased motility and survival of planktonic cells in the biofilms developed by $P$. extremaustralis under cold conditions. The PHB accumulation capability could constitute an adaptative advantage for the dispersion in stressful environments.

Acknowledgments This work was supported by grants from UBA and ANPCyT. N.I.L. is a career investigator from CONICET. P.M.T. has a graduate student fellowship from CONICET. We thank Karl G. Rueggeberg for his useful comments and language revision.

\section{References}

Albesa I, Becerra MC, Battan PC, Paez PL (2004) Oxidative stress involved in the antibacterial action of different antibiotics. Biochem Biophys Res Commun 317:605-609

Ayub ND, Pettinari MJ, Méndez BS, López NI (2006) Impaired polyhydroxybutyrate biosynthesis from glucose in Pseudomonas sp. 14-3 is due to a defective beta-ketothiolase gene. FEMS Microbiol Lett 264:25-131

Ayub ND, Pettinari MJ, Méndez BS, López NI (2007) The polyhydroxyalkanoate genes of a stress resistant Antarctic Pseudomonas are situated within a genomic island. Plasmid 58:240-248

Ayub ND, Tribelli PM, López NI (2009) Polyhydroxyalkanoates are essential for maintenance of redox state in the Antarctic bacterium Pseudomonas sp. 14-3 during low temperature adaptation. Extremophiles 13:59-66

Branda SS, Ashild V, Friedman L, Kolter R (2005) Biofilms: the matrix revisited. Trends Microbiol 13:20-26
Bylund J, Burgess LA, Cescutti P, Ernst RK, Speert DP (2006) Exopolysaccharides from Burkholderia cenocepacia inhibit neutrophil chemotaxis and scavenge reactive oxygen species. J Biol Chem 281:2526-2532

Caiazza NC, Merritt HJ, Brothers JM, O'Toole GA (2007) Inverse Regulation of Biofilm Formation and Swarming Motility by Pseudomonas aeruginosa PA14. J Bacteriol 189:3603-3612

Chang WS, Li X, Halverson LJ (2009) Influence of water limitation on endogenous oxidative stress and cell death within unsaturated Pseudomonas putida biofilms. Environ Microbiol 11:1482-1492

Chattopadhyay MK, Raghu G, Sharma YV, Biju AR, Rajasekharan MV, Shivaji S (2011) Increase in oxidative stress at low temperature in an Antarctic Bacterium. Curr Microbiol 62:544-546

Chesson P, Gebauer RL, Schwinning S, Huntly N, Wiegand K, Ernest MS, Sher A, Novoplansky A, Weltzin JF (2004) Resource pulses, species interactions, and diversity maintenance in arid and semi-arid environments. Oecologia 141:236-253

Cochran WL, McFeters GA, Stewart PS (2001) Reduced susceptibility of thin Pseudomonas aeruginosa biofilms to hydrogen peroxide and monochloramine. J Appl Microbiol 88:22-30

Costerton J, Lewandowski Z, Caldwell D, Korber D, Lappin-Scot H (1995) Microbial biofilms. Annu Rev Microbiol 49:711-745

D'Amico S, Collins T, Marx JC, Feller G, Gerday C (2006) Psychrophilic microorganisms: challenges for life. EMBO Rep 7:385-389

Decho AW (2000) Microbial biofilms in intertidal systems: an overview. Cont Shelf Res 20:1257-1273

Donlan G (2002) Biofilms: microbial life on surfaces. Emerg Infec Dis 8:881-890

Hazer B, Steinbüchel A (2007) Increased diversification of polyhydroxyalkanoates by modification reactions for industrial and medical applications. Appl Microbiol Biotechnol 74:1-12

Kadouri D, Jurkevitch E, Okon Y, Castro-Sowinski S (2005) Ecological and agricultural significance of bacterial polyhydroxyalkanoates. Crit Rev Microbiol 31:55-67

Klausen M, Heydorn A, Ragas P, Lambertsen L, Aaes-Jørgensen A, Molin S, Tolker-Nielsen T (2003) Biofilm formation by Pseudomonas aeruginosa wild type, flagella and type IV pili mutants. Mol Microbiol 48:1511-1524

Kohler T, Curty LK, Barja F, van Delden C, Pechere JC (2000) Swarming of Pseudomonas aeruginosa is dependent on cell-tocell signalling and requires flagella and pili. J Bacteriol 182:5990-5996

Lapaglia C, Hartzell PL (1997) Stress-induced production of biofilm in the hyperthermophile Archaeoglobus fulgidus. Appl Environ Microbiol 63:3158-3163

López NI, Floccari ME, Garcia AF, Steinbüchel A, Mendez BS (1995) Effect of poly-3-hydroxybutyrate content on the starvation survival of bacteria in natural waters. FEMS Microbiol Ecol 16:95-101

López NI, Pettinari MJ, Stackebrandt E, Tribelli PM, Pötter M, Steinbüchel A, Méndez BS (2009) Pseudomonas extremaustralis sp. nov. A poly(3-hydroxybutyrate) producer isolated from an Antarctic environment. Curr Microbiol 59:514-519

Lüthi E, Mercenier A, Haas D (1986) The $\operatorname{arcABC}$ operon required for fermentative growth of Pseudomonas aeruginosa on arginine: TnS-751-assisted cloning and localization of structural genes. J Gen Microbiol 132:2667-2675

Mah TF, O'Toole GA (2001) Mechanisms of biofilm resistance to antimicrobial agents. Trends Microbiol 9:34-39

Martinez P, Guzman J, Espin G (1997) A mutation impairing alginate production increased accumulation of poly- $\beta$-hydroxybutyrate in Azotobacter vinelandii. Biotech Lett 19:909-912

Matz C, Kjelleberg S (2005) Off the hook-how bacteria survive protozoan grazing. Trends Microbiol 13:302-307 
Ostle A, Holt JG (1982) Nile Blue A as a fluorescent stain for polyhydroxybutyrate. Appl Environ Microbial 44:238-241

O'Toole GA, Kolter R (1998) Flagellar and twitching motility are necessary for Pseudomonas aeruginosa biofilm development. Mol Microbiol 30:295-304

Pessi G, Haas D (2000) Transcriptional control of the hydrogen cyanide biosynthetic genes $h c n A B C$ by the anaerobic regulator ANR and the quorum-sensing regulators LasR and RhlR in Pseudomonas aeruginosa. J Bacteriol 182:6940-6949

Pham TH, Webb JS, Rehm BHA (2004) The role of polyhydroxyalkanoate biosynthesis by Pseudomonas aeruginosa in rhamnolipid and alginate production as well as stress tolerance and biofilm formation. Microbiology 150:3405-3413

Pratt LA, Kolter R (1998) Genetic analysis of Escherichia coli biofilm formation: roles of flagella, motility, chemotaxis and type I pili. Mol Microbiol 30:285-293

Quelas JI, López-García SL, Casabuono A, Althabegoiti MJ, Mongiardini EJ, Pérez-Giménez J, Couto A, Lodeiro AR (2006) Effects of N-starvation and C-source on Bradyrhizobium japonicum exopolysaccharide production and composition, and bacterial infectivity to soybean roots. Arch Microbiol 186:119-128

Ren Q, de Roo G, Witholt B, Zinn M, Thöny-Meyer L (2010) Influence of growth stage on activities of polyhydroxyalkanoate (PHA) polymerase and PHA depolymerase in Pseudomonas putida U. BMC Microbiol 10:254

Sauer K, Camper AK, Ehrlich G, Costerton JW, Davies DG (2002) Pseudomonas aeruginosa displays multiple phenotypes during development as a biofilm. J Bacteriol 184:1140-1154

Shrout JD, Chopp DL, Just CL, Hentzer M, Givskov M, Parsek M (2006) The impact of quorum sensing and swarming motility on
Pseudomonas aeruginosa biofilm formation is nutritionally conditional. Mol Microbiol 62:1264-1277

Simpson JA, Smith SE, Dean RT (1989) Scavenging by alginate of free radicals released by macrophages. Free Radical Biol Med 6:347-353

Strocchi M, Ferrer M, Timmis KN, Golyshin PN (2006) Low temperature-induced systems failure in Escherichia coli: insights from rescue by cold-adapted chaperones. Proteomics 6:193-206

Trevelyan WE, Harrison JS (1952) Studies on yeast metabolism. Fractionation and microdetermination of cell carbohydrates. Biochem J 50:298-303

Tribelli PM, Méndez BS, López NI (2010) Oxygen sensitive global regulator, Anr, is involved in biosynthesis of poly-3-hydroxybutyrate (PHB) in Pseudomonas extremaustralis. J Mol Microbiol Biotech 19:180-188

Van Alst N, Picardo K, Iglewski B, Haidaris C (2007) Nitrate sensing and metabolism modulate motility, biofilm formation, and virulence in Pseudomonas aeruginosa. Infect Immun 75:3780-3790

Wai S, Mizunoe Y, Takade A, Kawabata SI, Yoshida SI (1998) Vibrio cholerae O1 strain TSI-4 produces the exopolysaccharide materials that determine colony morphology, stress resistance, and biofilm formation. Appl Environ Microbiol 64:3648-3655

Wang H, Jiang X, Mu H, Liang X, Guan H (2007) Structure and protective effect of exopolysaccharide from $P$. agglomerans strain KFS-9 against UV radiation. Microbiol Res 162:124-129

Xu KD, Stewart PS, Xia F, Huang CT, McFeters GA (1998) Spatial physiological heterogeneity in Pseudomonas aeruginosa biofilms is determined by oxygen availability. Appl Environ Microbiol 64:4035-4039 